\title{
Pengelolaan Data Bahaya Bencana Tsunami Dalam Bentuk Webgis Di Kecamatan Seririt
}

\author{
Rusdianto ${ }^{1 *}$, I Wayan Treman 2 , I Wayan Krisna Eka Putra ${ }^{3}$
}

${ }^{1}$ Universitas Pendidikan Ganesha, Indonesia

${ }^{2}$ Universitas Pendidikan Ganesha, Indonesia

${ }^{3}$ Universitas Pendidikan Ganesha, Indonesia

\section{A R T I C L E I N F O}

\section{Article history:}

Received 28 July 2020

Received in revised form 20 August 2020

Accepted 30 August 2020

Available online 31 August 2020

\section{Kata Kunci:}

Data Spasial, Data Non-

Spasial, Webgis, Database,

MapServer.

\section{Keywords:}

Spatial Data, Non-Spatial

Data, Webis, Database,

MapServer

\section{A B S T R A K}

Penelitian dilaksanakan di Kecamatan Seririt Kabupaten Buleleng yang merupakan wilayah berpotensi terjadinya bencana tsunami yang kapan saja dapat terjadi, sebagian besar potensi tsunami yang akan terjadi ditimbulkan akibat terdapatnya patahan belakang Flores (back arc fault). Tujuan penelitian ini adalah: (1) mengetahui pengelolaan data spasial bahaya bencana tsunami untuk kebutuhan Webgis kecamatan Seririt Kabupaten Buleleng, (2) mengetahui pengelolaan data nonspasial, dan (3) menampilkan data spasial dan non-spasial bahaya bencana tsunami dalam bentuk webgis. Rancangan penelitian yang digunakan adalah pengembangan, menggunakan sumber data Peta dari Badan Penanggulangan Bencana daerah (BPBD) Kabupaten Buleleng. Metode pengumpulan data yang digunakan adalah metode studi pustaka dan observasi. Data di kembangkan dengan teknik metode pembuatan Sistem Development Life Cycle (SDLC) - Waterfall dengan analisis kebutuhan sistem. Hasil dari penelitian ini adalah fungsi tools dan menu fasilitas webgis yang berfungsi dengan baik akan tetapi pada saat testing di browser Internet Edge, atau Internet Explorer dan browser Google Chrome sistem aplikasi belum dapat berjalan dengan baik.

\section{A B S T R A C T}

The research was conducted in Seririt District, Buleleng Regency, which is a potential area for tsunami disasters that can occur at any time, most of the potential for tsunamis that will occur are caused by the presence of a back arc fault. The objectives of this study are: (1) knowing the spatial management of tsunami hazard data for the needs of Webgis Seririt sub-district of Buleleng Regency, (2) knowing the management of non-spatial data, and (3) displaying spatial and non-spatial data of tsunami hazard in the form of webgis. The research design used was development, using a map data source from the Regional Disaster Management Agency (BPBD) of the Regency of Buleleng. Data collection methods used are literature study and observation methods. The data is developed using the technique of making a System Development Life Cycle (SDLC) - Waterfall by analyzing the system requirements. The results of this study are testing tools and webgis facility functions are performed, but when testing in the Internet Edge browser, or Internet Explorer and the Google Chrome browser, the application system cannot run properly. 



\section{Pendahuluan}

Kabupaten Buleleng merupakan salah satu dari 8 kabupaten di Provinsi Bali yang memiliki potensi terjadinya bencana tsunami, setiap kabupaten di Provinsi Bali memiliki tingkat kerentanan dan risiko yang berbeda terhadap terjadinya bencana tsunami. Bencana tsunami dapat diartikan sebagai gelombang air laut yang merambat ke segala arah dan terjadi karena adanya gangguan impulsif pada dasar laut terjadinya bencana tsunami menimbulkan ombak laut yang berbeda dari biasanya kita terjadinya genangan air akibat dari hempasan air laut ke darat, BMKG (2012). Akibat genangan air laut yang ditimbulkan dari adanya bencana tsunami dapat berakibat pada kerusakan pada kondisi fisik, lingkungan ataupun sosial di daerah yang terdampak mengingat Sebagian besar masyarakat yang ada di provinsi Bali bertempat tinggal atau bermukim di daerah yang tidak jauh dari pesisir pantai yang berpotensi terkena hempasan ombak tsunami dan genangan air akibat hempasan air laut yang diakibatkan oleh bencana tsunami.

Potensi bencana tsunami yang terjadi di masing-masing kabupaten di Provinsi Bali banyak diakibatkan oleh letak pantai masing-masing kabupaten di bagian utara dekat dengan zona subduksi tumbukan antara lempengan Indo- Australia dan lempengan Eurasia. Bagian Utara seperti letak pesisir pantai di Kabupaten Buleleng dan letak Kecamatan Seririt yang sebagian besar potensi tsunami yang akan terjadi ditimbulkan akibat terdapatnya patahan belakang yang (back arc fault) atau patahan belakang Flores (dokumen taktis provinsi Bali tahun 2010).

Secara geografis Kecamatan Seririt merupakan wilayah daratan rendah yang sempit di bagian utara dan perbukitan di bagian Selatan. Banyaknya aktivitas masyarakat Kecamatan Seririt yang berada di daerah dataran rendah (low land) yang letaknya tidak jauh dari pesisir pantai bagian utara yang rentan terdampak bencana tsunami akibat terdapatnya patahan belakang (back arc fault), perlu dilakukan langkah mitigasi untuk mengurangi dampak risiko bencana yang ada dengan membuat sistem informasi geografis (SIG) tambahan yang memuat informasi bahaya bencana tsunami dan dapat menjangkau lebih banyak masyarakat dengan berbasis webgis. Pemetaan berbasis webgis atau web mapping merupakan salah satu hasil pemanfaatan yang ada pada SIG yang disajikan dalam bentuk interface web. webgis bahaya bencana tsunami di Kecamatan Seririt merupakan bentuk salah satu produk aplikasi SIG yang dapat dijalankan ada web browser Penampilan webgis bahaya bencana tsunami dapat dikelolah dengan memanfaatkan pengelolaan data spasial dan non-spasial dari Badan Penanggulangan Bencana Daerah (BPBD) Kabupaten Buleleng yang sudah ada dalam bentuk peta dan di proses menjadi shapefile dan diletakkan kedalam geodabase postgreeSQL untuk dapat ditampilkan pada webgis.

Permasalahan pada penelitian ini (1) Bagaimana pengelolaan data spasial bahaya bencana tsunami untuk kebutuhan webgis bahaya bencana tsunami kecamatan Seririt Kabupaten Buleleng, (2) Bagaimana pengelolaan data non-spasial bahaya bencana tsunami untuk kebutuhan webgis bahaya bencana tsunami Kecamatan Seririt Kabupaten Buleleng, (3) Bagaimana menampilkan data bahaya bencana tsunami dalam bentuk webgis di Kecamatan Seririt Kabupaten Buleleng. Tujuan dari penelitian (1) Mengetahui pengelolaan data spasial bahaya bencana tsunami untuk kebutuhan Webgis kecamatan Seririt Kabupaten Buleleng, (2) Mengetahui pengelolaan data non-spasial bahaya bencana tsunami untuk kebutuhan Webgis Kecamatan Seririt Kabupaten Buleleng, (3) Menampilkan data spasial dan non-spasial bahaya bencana tsunami dalam bentuk webgis di Kecamatan Seririt Kabupaten Buleleng.

\section{Metode}

Penelitian menggunakan data skunder dengan metode penelitian menggunakan metode klasik SDLC (System Development Life Cycle) dengan model proses waterfall, pengembang dapat melakukan pengembangan produk secara bertahap dengan tingkat kesalahan dapat diperkecil sehingga produk yang diharapkan dapat sesuai dengan yang diharapkan (Prahasta, 2009).

Pengumpulan data spasial (shapefile) bencana tsunami di Kecamatan Seririt dilakukan dengan cara georefrencing dan digitasi dengan menggunakan software ArcGis10.3, peta tematik yang dilakukan proses georefrencing dan digitasi di ArcGis 10.3 diperoleh dari peta evakuasi bencan tsunami Kecamatan Seririt yang dipublikasikan oleh Badan Penanggulangan Bencana Daerah (BPBD) Kabupaten Buleleng dalam bentuk softcopy, dari proses tersebut akan didapatkan data shapefile zona aman bencana tsunami, data shapefile zona bahaya tsunami dan data titik lokasi titik kumpul evakusi jika sewaktu-waktu terjadi bencana tsunami di Kecamatan Seririt. sedangkakan data non-spasial diperoleh dari banyak sumber seperti dari dokumen taktis bencana tsunami Provinsi Bali, observasi langsung kelapangan sehingga didapatkan data atribut yang digunakan untuk kelengkapan informasi spasial.

Pengupulan data skunder dilakukan dengan observasi awal Memperoleh kajian teoritis sebagai dasar untuk melakukan penelitian terkait dengan pembangunan sistem informasi geografis berbasis web bahaya bencana tsunami dan studi pustaka mengidentifikasi permasalahan di daerah rawan bencana 
tsunami berpaku pada peta evakuasi bencana tsunami yang bersumber dari BPBD terkait dengan pembangunan sistem informasi geografis berbasis web bahaya bencana tsunami.

\section{Hasil dan pembahasan}

Langkah awal pengembangan basis data webgis yaitu dengan membuat Context Diagram (Prahasta, 2009), pengelolaan data bahaya bencana tsunami yang merupakan gambaran secara umum untuk mengidentifikasikan komponen-komponen Webgis bahaya bencana tsunami di Kecamatan Seririt secara terinci seperti terlihat pada Tabel 1.

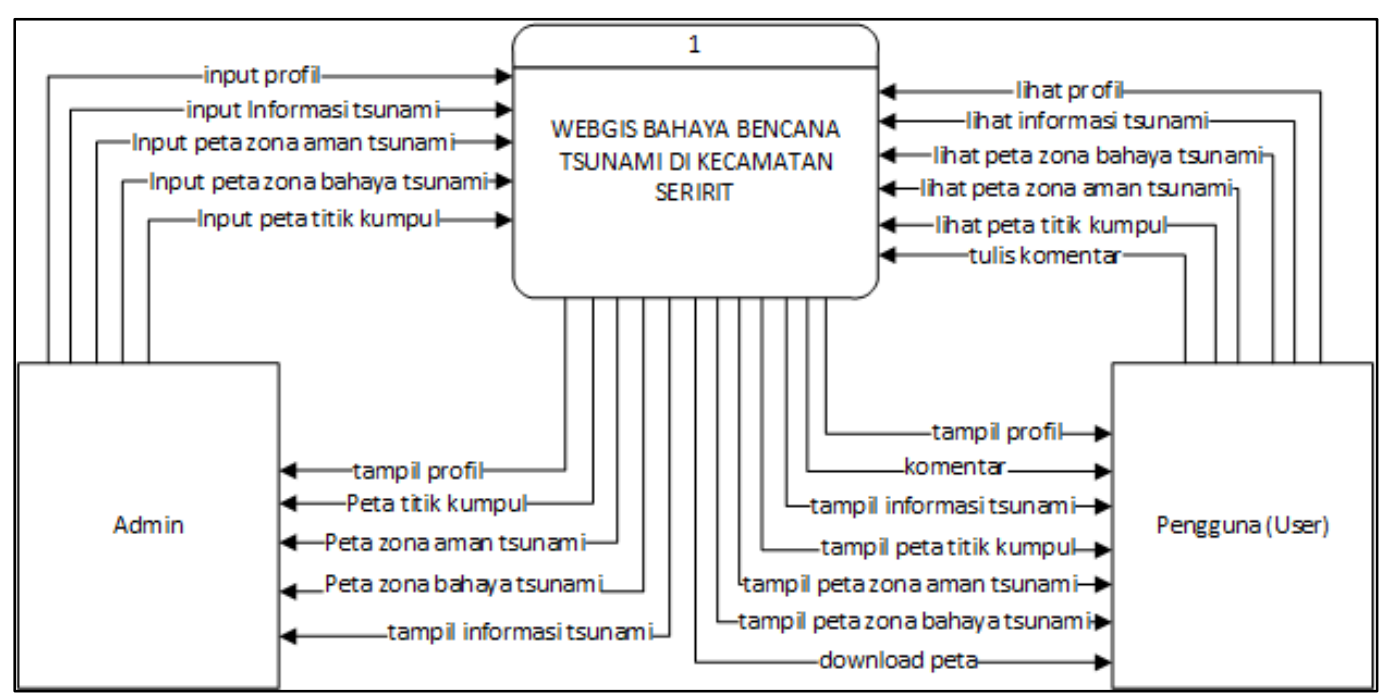

Gambar 1. Context Diagram

Konteks Diagram diatas dapat dilihat bahwa proses yang terjadi dalam Webgis bahaya bencana tsunami di Kecamatan Seririt melibatkan dua sumber atau tujuan data yaitu admin, dan pengguna. Setelah merancang DFD yang menggambarkan secara umum tentang webgis, selanjutnya merancang DFD Level 1dan DFD Level 2 yang menggambar secara lebih terperinci tentang webgis yang dibuat (Sutabri, 2004), gambaran DFD Level 1 seperti terlihat pada Tabel 2.

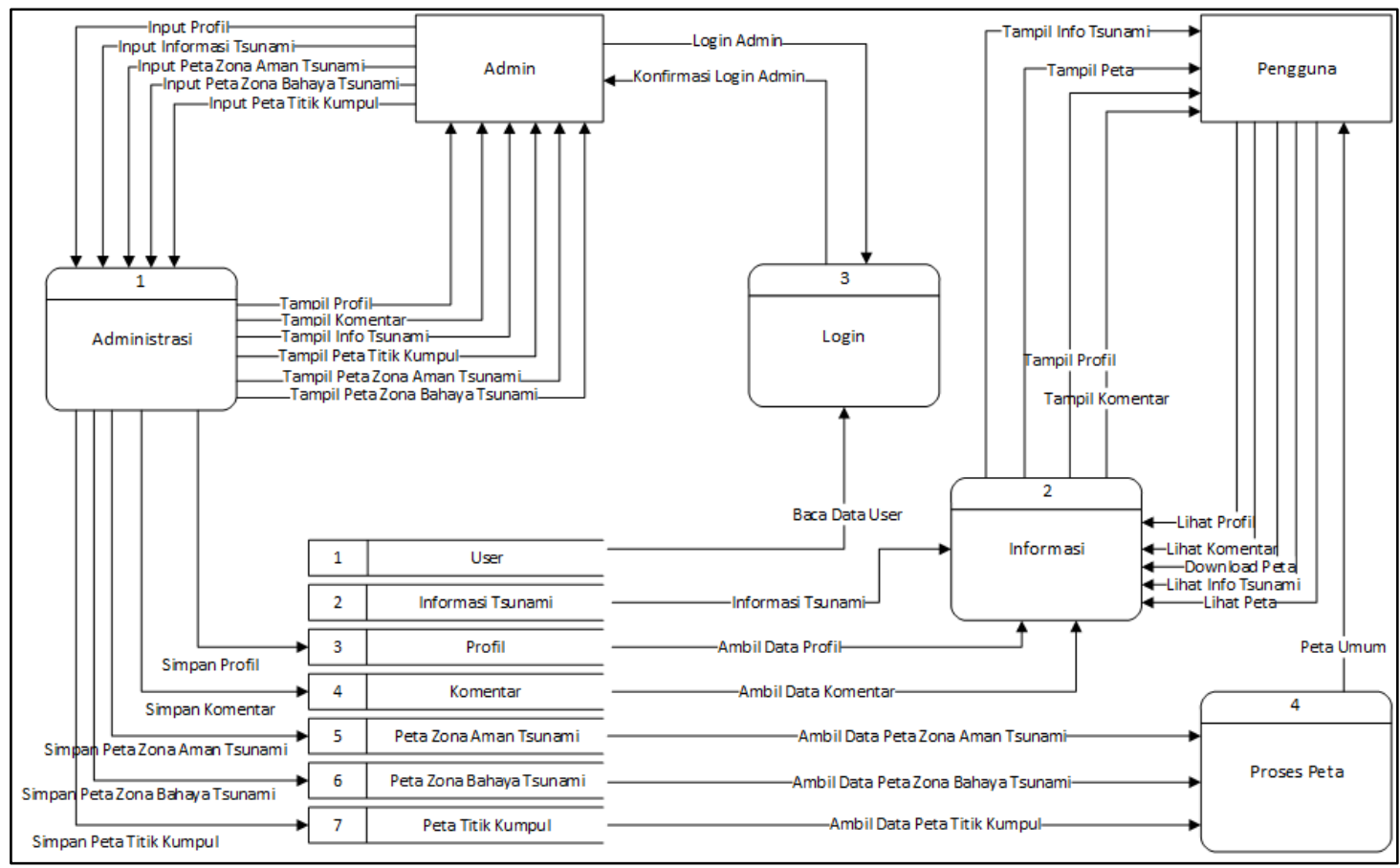

Gambar 2. DFD Level 1 Proses Peta 
DFD level 1 Webgis bahaya bencana tsunami di Kecamatan Seririt terdapat empat proses yang dilakukan oleh admin dan pengguna. (1) Proses 1 adalah administrator berfungsi untuk melakukan manajemen data yang akan ditampilkan di webgis, (2) Proses 2 adalah informasi yang merupakan proses untuk melakukan penampilan informasi ke pengguna, (3) Proses 3 adalah login user meupakan proses pintu masuk memasukkan identitas akun bagi untuk mengelola content database. (4) Proses 4 proses yang menangani seluruh data peta didalam database untuk di panggil dan tampilkan ke pengguna.webgis. Penggambaran berikutnya yaitu dengan membuat DFD Level 2 seperti terlihat pada Gambar 3.

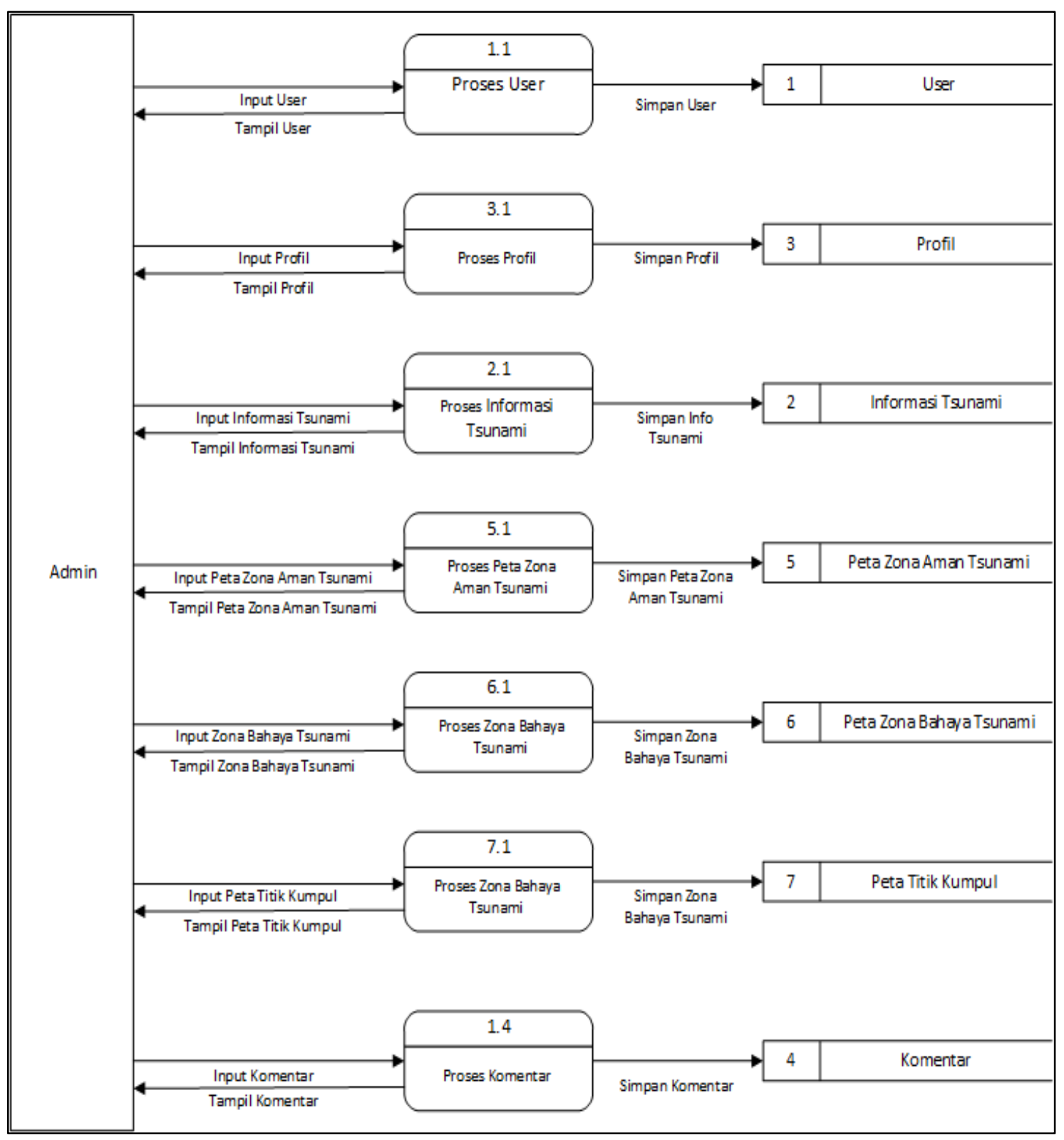

Gambar 3 DFD Level 2 Peta Bencana Bahaya Tsunami di Kecamatan Seririt

DFD level 2 menampilkan penjelasan lebih terperinci dari proses pengembangan webgis yang terdapat pada level 1. Ditampilkan penjelasan mengenai proses melakukan penyimpanan ke database data profil, tulisan informasi mengenai bencana tsunami, data peta zona aman bencana tsunami, peta bahaya bencana tsunami, peta titik kumpul yang akan ditampilkan.

Memperoleh data spasial dapat dilakukan dari peta softcopy bahaya bencana tsunami di Kecamatan Seririt, dengan melakukan serangkaian pengelolaan menggunakan software pemetaan seperti penggunaan 
software ArcGIS untuk melakukan proses georefrencing dan digitasi untuk memperoleh data shapefile dengan tiga format berbeda yaitu *shp, ${ }^{*} \operatorname{shx}, *$ def.

Pengelolaan data spasial dengan terlebih dahulu dilakukan dengan georefencing dan digitasi peta bahaya bencana tasunami di Kecamatan Seririt tahun 2010, dengan menggunakan software AcGIS 10.3 sehingga diperoleh data spasial berupa data poligon, titik dan garis yang mencerminkan informasi tentang zona bahaya, zona aman, titik kumpul dan jalur evakuasi yang secara terperinci di tampilkan pada tabeltabel ERD untuk mempermudah mendesain database spasial, langkah berikutnya yaitu melakukan pengelolaan data non spasial untuk mendesain database nun-spasial yang akan di tampilkan di webgis.

Pengelolaan data non-spasial diperlukan agar dalam desain database dapat dilakakukan dengan baik, pembuatan database dengan penyajian pada tabel ERD yang merincikan alur database data pengguna webgis dan data komentar yang dapat dimanfaatkan untuk kebutuhan informasi pengembangan webgis lebih baik lagi. Pada tahap selanjutnya setelah diperoleh data spasial dan merancang desain database spasial dan non-spasial langkah berikutnya yaitu penampilan webgis bahaya bencana tsunami.

Diperolehnya data shapefile dapat proses untuk di manajemen ke dalam database menggunakan software Posgre SQL dengan format pgsql dan dapat dikonversi kembali ke dalam ukuran yang lebih kecil dengan serangkaian perintah di commad prompt.

Pembuatan prototipe webmapping dan interface website untuk ditampilkan pada browser dilakukan dengan menggunakan software Mapserver (MS4W) dengan freamwork Pmapper sebagai webmapping open source dengan terdapat banyak freamwork yang ringan dengan fasilitas tool peta yang sudah tersedia hanya tinggal menghubungkan ke geodatabase untuk menampilkannya (Nuryadin, 2005), sedangkan untuk membangun interface website dapat dengan menggunakan software dreamweafer.

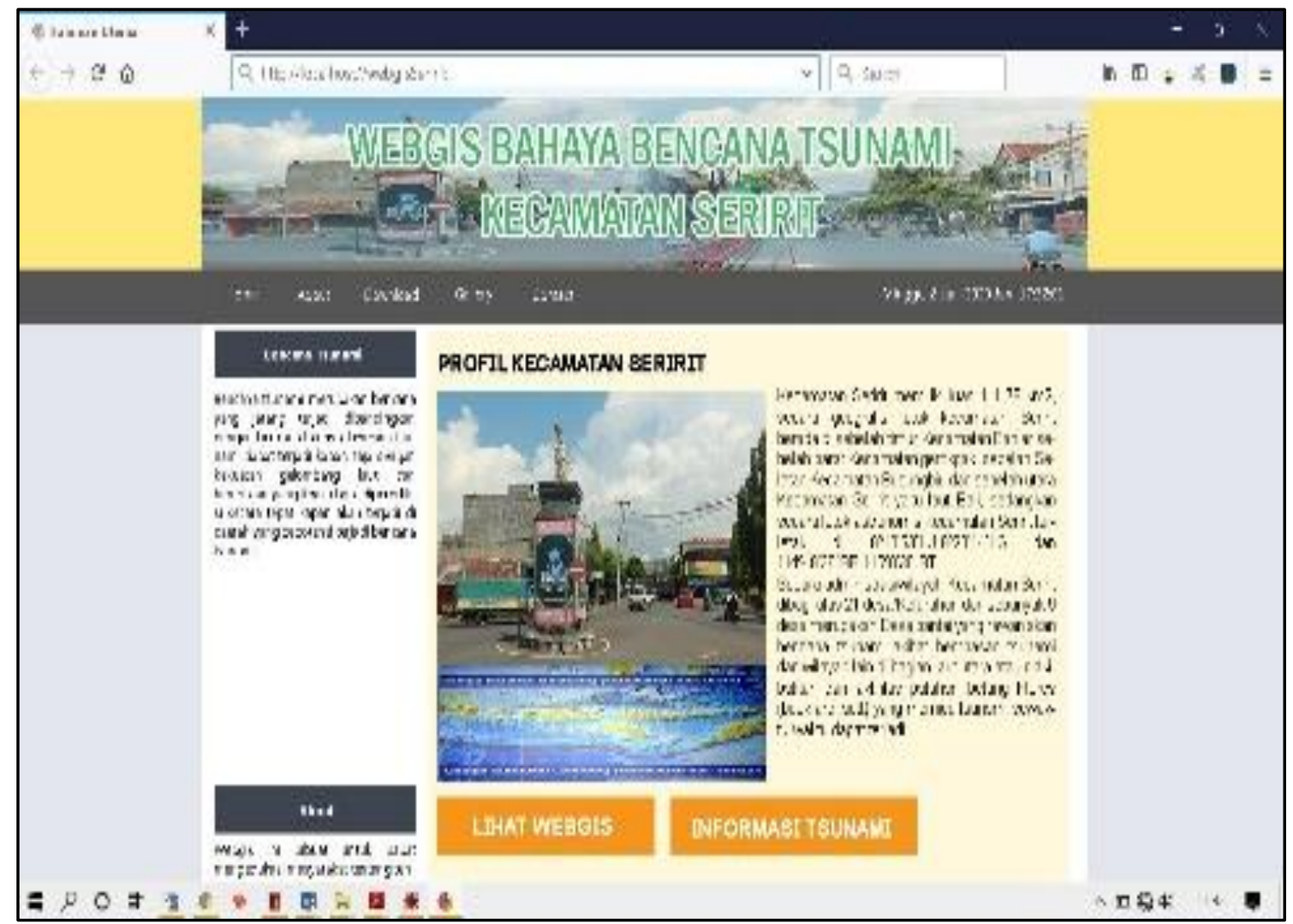

Gambar 4. Tampilan Halaman Utama Website

Tampilan pada halaman utama webgis terdapat informasi mengenai profil Kecamatan Seririt yang memiliki potensi akan bahaya bencana tsunami dari Laut Bali di bagian utara dan terdapat dua menu di bawah profil untuk menuju ke halaman webgis peta bahaya tsunami di Kecamatan Seririt dan menu untuk informasi lebih lanjut mengenai bahaya bancana tsunami. Pada halaman utama juga terdapat tombol menuju halaman lain, Hidayatullah (2017) desain website yang baik dapat dibuat dengan terdapat menu yang menfasiltasi pengguna agar dapat mendapat informasi yang diperlukan, pada halam utama webgis terdapat menu yaitu menuju halaman "About", Download Peta", "Gallery", "Contact" dan "login". Tampilan untuk setiap halaman tersebut digambarkan pada Gambar 5 


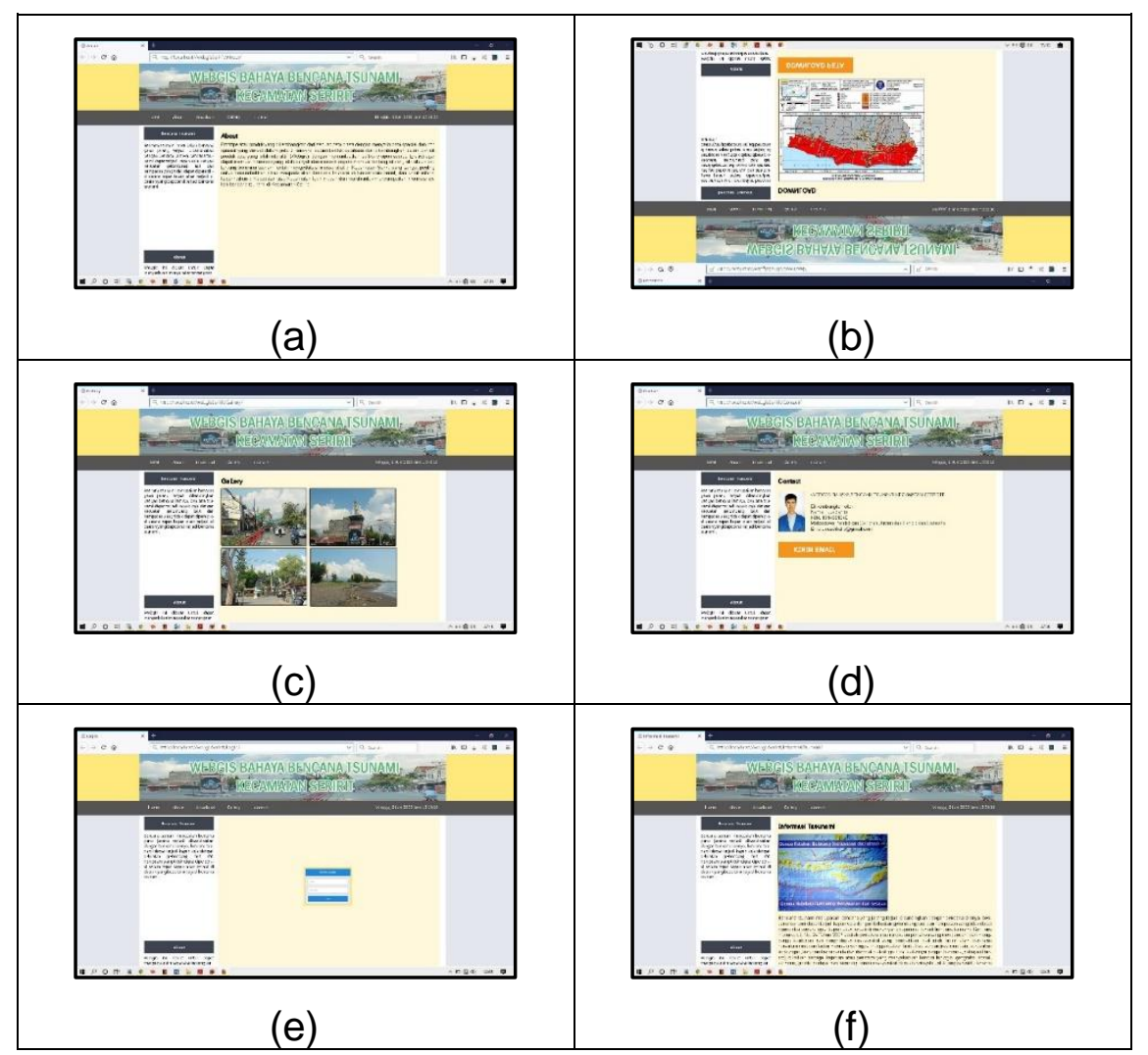

Gambar 5. Tampilan Halaman (a) About, (b) Download, (c) Galley, (d) Contact, (e) login, (f) Informasi Tsunami

Halaman informasi tsunami pengguna akan ditampilkan sebuah informasi mengani bencana tsunami secara umum, bahaya bencana tsunami di Kecamatan Seririt, dan cara mengevakuasi diri jika sewaktu-waktu terjadi bencana tsunami di Kecamatan Seririt sesuai dengan yang telah di sarankan oleh BPBD Kabupaten Buleleng. Halaman selanjutnya adalah halaman webgis bahaya bencana tsunami di Kecamatan Seririt seperti Gambar 6.

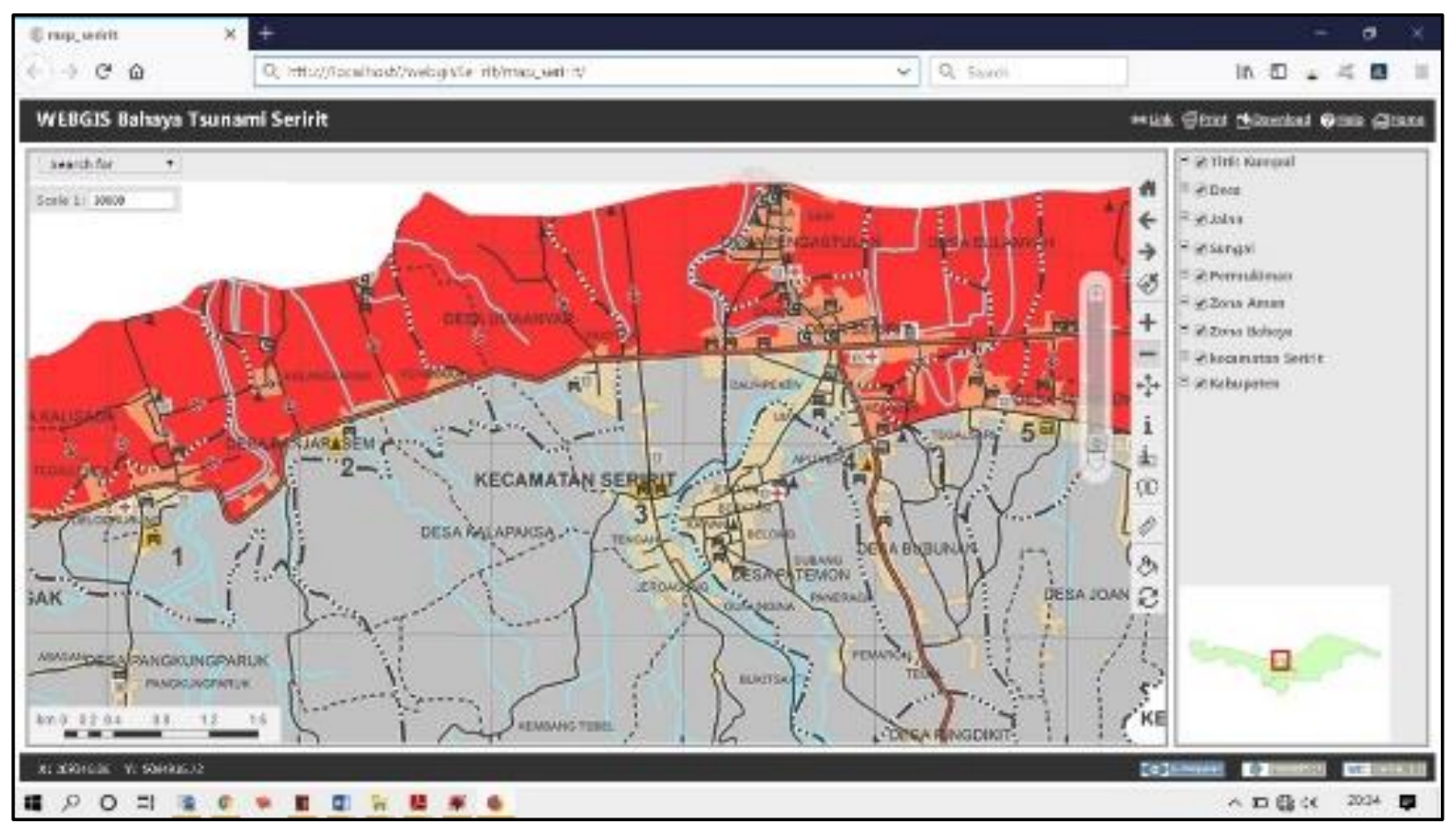

Gambar 6. Tampilan Halaman Webgis Bahaya Bencana Tsunami di Kecamatan Seririt 
Halaman ini ditampilkan peta bahaya bencana tsunami di Kecamatan Seririt, yang didalamnya dimuat tentang informasi peta zona bahaya tsunami di kecamatan Seririt yang harus dihindari ketika terjadi bencana tsunami karena tergolong daerah dataran rendah, zona aman bahaya tsunami di informasikan dengan bentuk poligon warna merah, informasi zona aman bencana tsunami dengan warna abu-abu yang merupakan daerah dataran tinggi, titik kumpul diberikan simbol berwarna kotak berwarna orange (jingga), informasi jalan dengan simbol garis berwana hitam, informasi sungai dengan simbol garis berwarna biru, dan permukiman berwarna coklat. Pada layar webgis.

Setelah tampilan webgis selesai dibuat maka dilakukan serangkaian testing produk webgis dengan menggunakan software testing untuk mengujinya (Pressman, 2002), dari software testing dengan model white box dan black box kerentanan bencana tsunami di Kecamatan Seririt diperoleh produk prototipe dengan tools yang berfungsi dengan baik akan tetapi pada saat testing di browser Internet Edge, atau Internet Explorer dan browser Google Chrome sistem aplikasi belum dapat berjalan dengan baik.

\section{Simpulan dan saran}

Pengolahan data spasial bahaya bencana tsunami di Kecamatan Seririt yang akan ditampilkan di webgis di peroleh dengan proses georefrencing dan digitasi untuk memperoleh data shapefile dengan tiga format berbeda yaitu *shp, *shx, *def, agar tertata sesuai dengan kebutuhan sistem diperlukan pembuatan Entity Relationship Diagram (ERD) Spasial yang penggambaran secara grafis hubungan dengan entitas untuk mendesain basis data spasial, data spasial bahaya bencana tsunami yang dikelolah dengan database spasial dengan software PostGis dan dapat berjalan dengan baik untuk memuat data poligon yang mereprensentasikan data zona aman bencana tasunami, zona baha bencana tsunami dan wilayah Kecamatan Seririt, memuat dengan baik data garis yang mereprensentasikan data jalan dan sungai dan memuat dengan baik dat titik kumpul lokasi aman dari terjangan bencana tsunami.

Pengolahan data non-spasial yang memuat data masukan komentar, saran dan data pengguna untuk dapat memberikan masukan informasi tambahan mengenai data atribut bahaya bencana tsunami guna pengembangan webgis lebih baik lagi, manajemen database data non-sapasial dapat berjalan dengan baik dengan memanfaatkan PostgreeSQL sebagai database karena terdapat fasilitas manajemen data yang lengkap seperti menambah dan menyisipkan tabel baru dengan mudah (The PostgreSQL Global Development Group, 2014).

Penampilkan informasi bahaya bencana tsunami dalam bentuk webgis dengan mengkonversi terlebih dahulu database spasial dan non spasial ke format pgsql agar dapat dibaca oleh software Mapserver (MS4W) dengan freamwork Pmapper, untuk membuat interface website menggunakan software dreamweafer. Hasil testing tools dan berfungsi webgis dapat dengan baik di browser Mozilla firefox akan tetapi pada saat testing di browser Internet Edge, atau Internet Explorer dan browser Google Chrome kurang dapat berjalan dengan baik.

Saran penulis tahu dalam aplikasi Sistem Informasi Geografis berbasis webgis dengan memanfaatkan data peta yang sudah ada lalu di konversi ke geodatabase sehingga dapat dimanfaatkan untuk membuat produk webgis bahaya bencana tsunami di Kecamatan Seririt ini masih banyak terdapat kelemahan dan kekurangan. Oleh sebab itu penulis mengharapkan untuk penelitian selanjutnya sistem ini dapat agar webgis dapat cepat diakses kopatibel dengan banyak software browse, bahasa pemprograman yang lebih diperbaiki susun bobotnya agar tidak terasa lambat dan penggunaan software pengolahan yang lebih baru dan mudah namun menghasilkan webgis dengan interface menarik, dinamis dan responsif agar masyarakat dapat mengakses dengan nyaman dan cepat.

\section{Daftar Rujukan}

Badan Nasional Penanggulangan Bencana. 2011. Indeks Rawan Bencana Indonesia. (Tidak diterbitkan). Jakarta: BNPB.

Badan Meteorologi Klimatologi dan Geofisika. 2012. Pedoman Pelayanan Peringatan Dini Tsunami. Jakarta: BMKG,

DLR/GTZ. 2010. Peta Bahaya Tsunami Bali, Peta Bahaya Tsunami Multi-Skenario Bali, skala 1:100.000, Peta Bahaya Tsunami Multi-Skenario Bali Selatan, Skala 1:25.000, dengan Zonasi Berdasarkan Ketinggian Gelombang di Pantai (Sejalan dengan Tingkat Peringatan INATEWS) dan Peluang (Probabilitas) Area yang akan Terdampak Tsunami Besar. Bali: Kelompok Kerja untuk Pemetaan Bahaya Tsunami.

Hidayatullah, P dan Kawistra Jauhari K. 2017. Pemprograman WEB. Bandung: Bandung Informatika.

Nuryadin, Ruslan. 2005. Panduan Menggunakan MapServer. Bandung: Bandung Informatika. 
Peta Evakuasi Tsunami Kecamatan Seririt Kabupaten Buleleng oleh BPBD Kabupaten Buleleng Tahun 2010

Prahasta, Eddy. 2005. Sistem Informasi Geografis: Konsep-Konsep Dasar Sistem Informasi Geografis. Bandung: Bandung Informatika

Prahasta, Eddy. 2007. Sistem Informasi Geografis, Membangun Aplikasi Web-Based GIS dengan MapServer, Bandung: Bandung Informatika

Prahasta, Eddy. 2009. Sistem Informasi Geografis, Konsep-Konsep Dasar (Perspektif Geodesi dan Geomatika), Bandung: Bandung Informatika

Prahasta, Eddy. 2012. Tutorial PostGreSQL, PostGIS dan pgRouting, Bandung: Bandung Informatika

Pressman, Roger S. 2002. Rekayasa Perangkat Lunak: Pendekatan praktisi (buku I). Yogyakarta: Andi.

Sutabri, Tata. 2004. Analisis Sistem Informasi. Yogyakarta: ANDI.

The PostgreSQL Global Development Group, (2014), PostgreSQL 9.1.14 Documentation, University of California, California. 